\title{
LONG-TERM ANALYSES OF AEROSOL OPTICAL THICKNESS USING CALIOP
}

\author{
Masahiro Fujikawa ${ }^{1}$, Rei Kudo ${ }^{2}$, Tomoaki Nishizawa ${ }^{3}$, Eiji Oikawa ${ }^{4}$, \\ Akiko Higurashi $^{3}$, Hajime Okamoto ${ }^{4}$ \\ ${ }^{1}$ Kyushu University Interdisciplinary Graduate School of Engineering Sciences, 6-1 Kasuga Park, \\ Kasuga, Fukuoka 816-8580, JAPAN *Email: fujikawa@riam.kyushu-u.ac.jp \\ ${ }^{2}$ Meteorological Research Institute, 1-1 Nagamine, Tsukuba, Ibaraki 305-0052, JAPAN \\ ${ }^{3}$ National Institute for Environmental Studies, 16-2 Onogawa, Tsukuba, Ibaraki 305-0053, JAPAN \\ ${ }^{4}$ Kyushu University Research Institute for Applied Mechanis, 6-1 Kasuga Park, Kasuga, Fukuoka 816- \\ 8580, JAPAN
}

\begin{abstract}
We developed an algorithm to derive extinction coefficients for four aerosol components (watersoluble, dust, sea salt, black carbon) from CloudAerosol Lidar with Orthogonal Polarization (CALIOP) data. The algorithm was applied to the nine-year data for 2007-2015 and the results were compared to CALIOP standard product (CALIOP-ST) and MODerate resolution Imaging Spectroradiometer (MODIS) standard product (MODIS-ST). Comparisons of the total aerosol optical thickness (AOT) showed that MODIS-ST was the largest, followed by CALIOP-ST (Ver.4), and our product. CALIOP-ST (Ver.3) showed a similar magnitude to ours.
\end{abstract}

\section{INTRODUCTION}

Uncertainties of a climatic impact of aerosols are large. It is therefore highly demanded to have reliable observing systems and analyses of the global spatiotemporal distribution of optical and microphysical properties of aerosols. The observation by the two-wavelength polarization Mie scattering lidar CALIOP onboard CloudAerosol Lidar and Infrared Pathfinder Satellite Observations (CALIPSO) satellite has exceeded 12 years and it provides long-term fluctuation of the global three-dimensional distribution of the aerosols.

The optical and microphysical properties of aerosols differ greatly depending on their chemical composition. Thus, identification of aerosol components has to be conducted to assess the climate effects of aerosols. A method to determine major aerosol species in the atmosphere using two-wavelength polarized Mie scattering lidar data has been developed using data from JAMSTEC research vessel MIRAI and groundbased lidar network AD-Net [1. 2, 3]. The algorithm was further extended to be applied to CALIOP data [4]. This method identifies four aerosol components, water-soluble particles (WS), mineral dust (DS), sea salt particles (SS), and internally mixed black carbon particles (LAC) and estimates vertical profiles of extinction coefficients for four aerosol components.

\section{Method}

We rely on the results from Aerosol detection and cloud screening in NASA-CALIOP ST products. However, our retrieval algorithm for aerosol microphysics is different from the NASA CALIOP standard algorithm. Our method uses all the measurement channels of the CALIOP: total attenuated backscattering coefficient $(B)$ at 532 and $1064 \mathrm{~nm}$ and the depolarization ratio $(\delta)$ at $532 \mathrm{~nm}$ (CALIOP Level 1B Version 3 product). Note that the NASA standard algorithm uses $B$ and $\delta$ at $532 \mathrm{~nm}$. Maximum a posteriori (MAP) method is used to reduce estimation errors due to signal noise and to suppress the generation of meaningless solutions [5]. Following assumptions and modeling have been made for their shapes, size distributions, and refractive indexes to estimate extinction coefficients of four aerosol components from three-measurement channels. The shape of DS is assumed to be a spheroid; and the others are spherical. The particle size distribution is expressed as a log-normal distribution; the mode radii and variances are prescribed according to studies in [6] and [7]. As for LAC, Core-Gray-Shell (CGS) model [8] is applied where black carbon is assigned as the core and 
WS as the shell. The dry mode radius of LAC is the same as WS. The mode radius of SS is estimated from the wind speed at sea level [9]. The complex refractive indices of WS and SS are adopted from the values of a database [6], and those of DS are taken from the values of Asian dust observation [10]. In addition, optical and microphysical properties of WS, SS, and LAC are modeled depending on humidity [6].

This algorithm is applied to the CALIOP data after removing the data contaminated by cloud using Cloud and aerosol masks (CALIOP Level 2 VFM Version 3 product).

\section{Results}

We applied the algorithm to the CALIOP data and evaluated annual mean global distributions of the clear-sky aerosol optical thickness (AOT) at 532 $\mathrm{nm}$ of four aerosol components (WS, SS, DS, and LAC) and total AOT (Fig.1). The total AOT (Fig.1e) is larger (around 0.3-0.5) in low to midlatitudes, such as in China, India, the Middle East, Africa, and South America. It is found that the contributions of WS (Fig.1a) and DS (Fig.1c) are large.

(a)

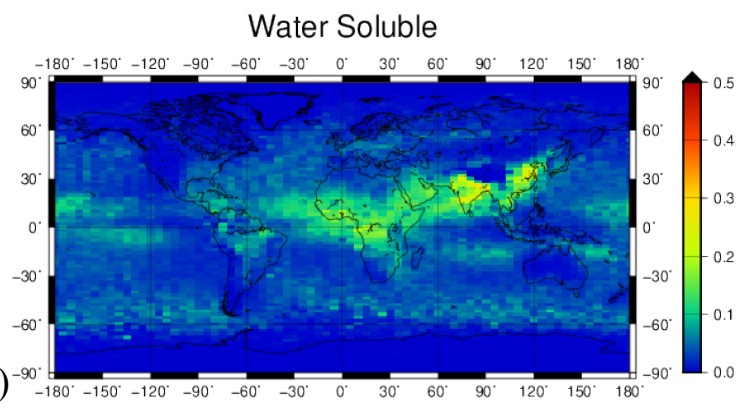

(b)

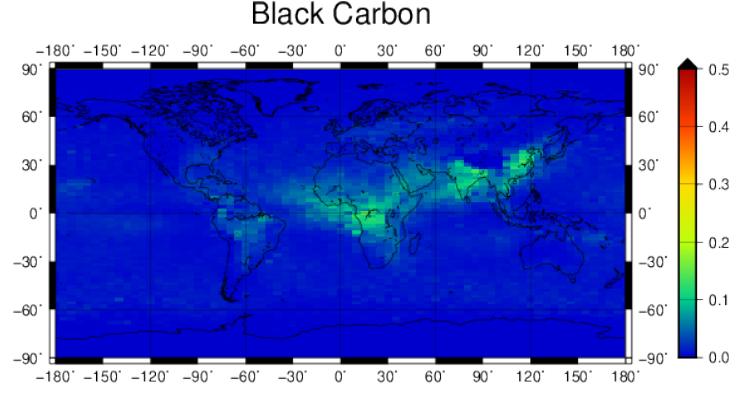

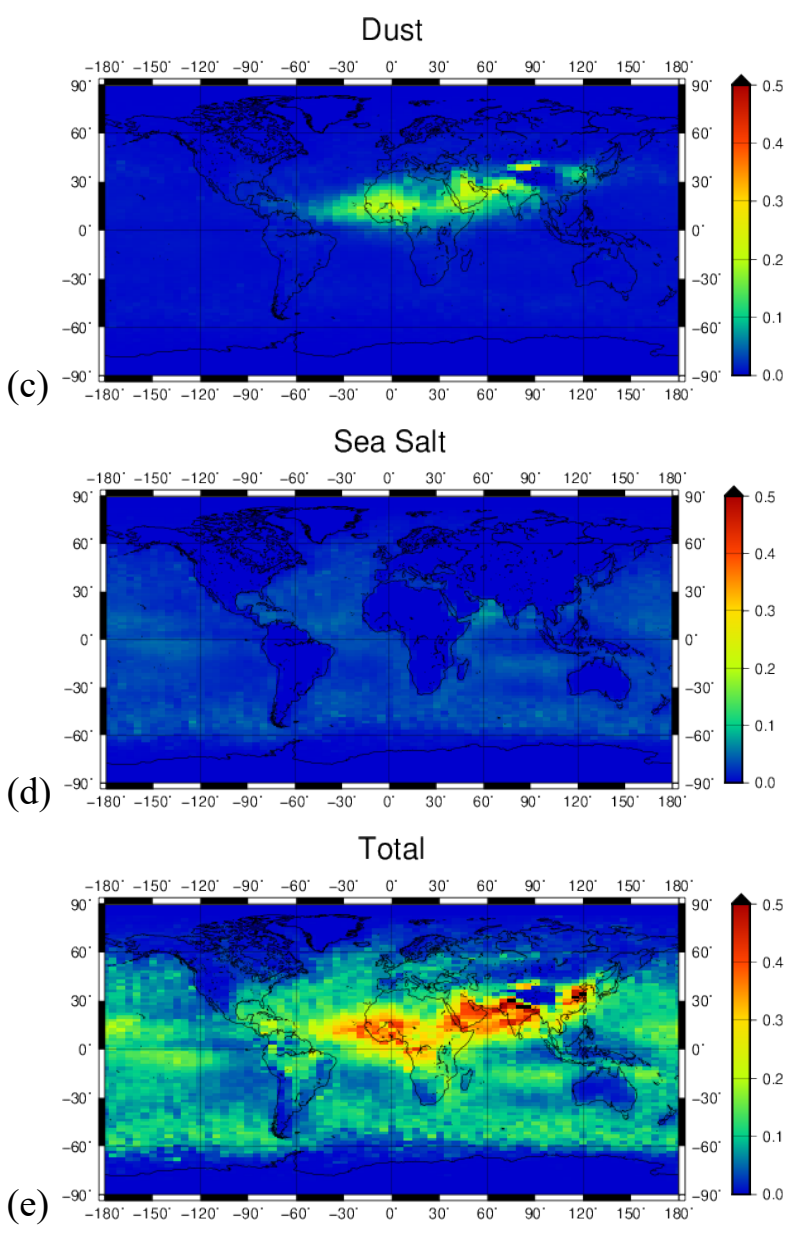

Figure 1. The annual mean clear-sky aerosol optical thickness (AOT) in 2010 during day-time from this study where the resolution of latitude $2^{\circ}$ - longitude 5o. (a) Water Soluble, (b)LAC (Black Carbon), (c)Dust, (d)Sea Salt, (e)Total.

We compared these results with the other satellite products. Figure 2 shows total AOTs of CALIOP NASA standard products (CALIOP-ST) Version 3 (Ver.3) and Version 4 (Ver.4) and MODIS standard product (MODIS-ST). The geographical pattern of total AOT is similar to our product, CALIPSO-ST, and MODIS-ST. Total AOT of our product is comparable to those of CALIPSO-ST Ver.4 and MODIS-ST and larger than CALIPSO ST Ver.3 over the ocean. In Sahara and Arabian deserts, total AOT is smaller than 0.5 in our product, CALIPSO-ST Ver.3, and MODIS-ST, while that in CALIOP-ST Ver.4 is larger than 0.5.

Finally, 9 years of analyses of total AOT are conducted from 2007 to 2015 (Fig.3). CALIPSO 
AOT for our product is smaller than MODIS AOT throughout the whole period. MODIS AOT tends to be overestimated by about 10 to $20 \%$, because of cloud contamination of thin cirrus [11]. CALIOP AOT is smaller than MODIS AOT by $20-40 \%$ even after accounting for the cloud contamination effect of the passive sensor. In addition, it is found that the global mean AOTs of MODIS-ST and CALIOP-ST are relatively constant. Contrary to these two products, our CALIOP Ver.3 product shows large fluctuations from 2012 to 2013 . When we use Ver.4 product as input, such fluctuation is found in the product. The possible reason for the time variation of our retrieved AOT is the minor update of the CALIOP Level 1B product from Version 3.02 to 3.30 .

(a)

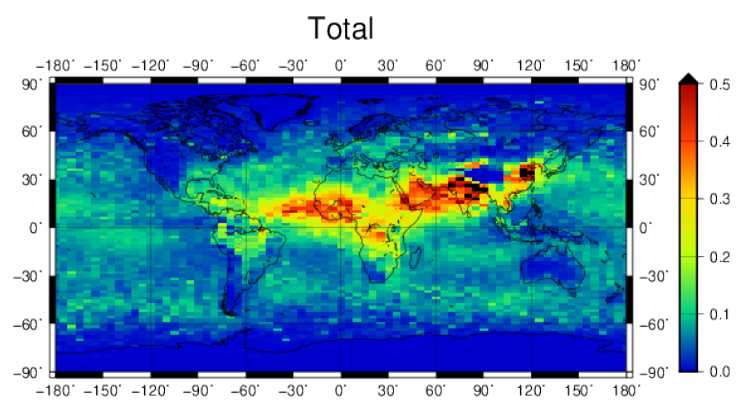

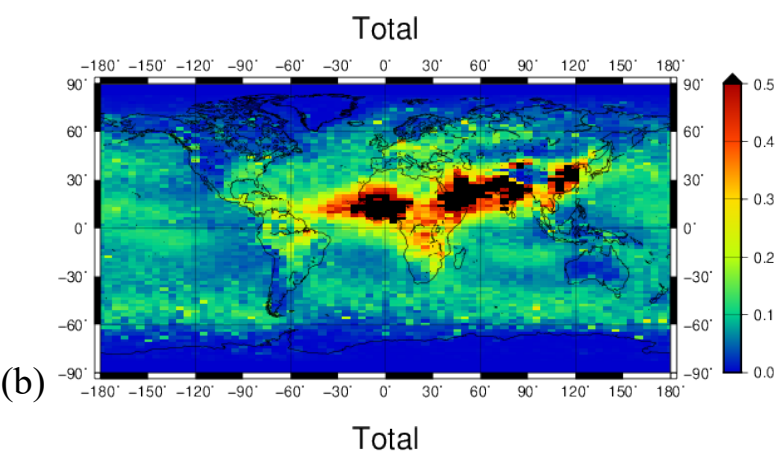

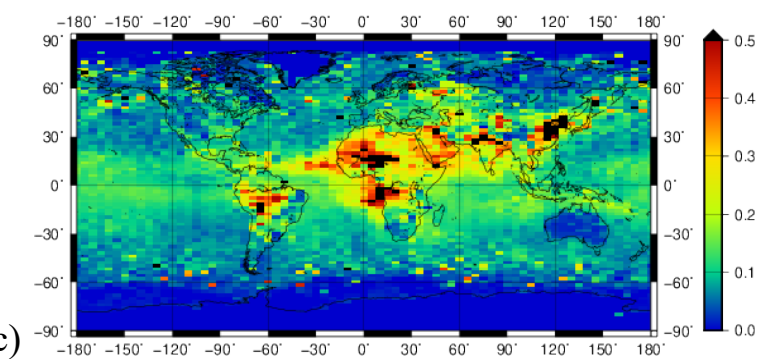

Figure 2. Same as Fig. le but (a) CALIOP NASA standard product Version 3 (CALIOP-ST Ver.3), (b) CALIOP NASA standard product Version 4 (CALIOP-ST Ver.4), and (c)MODIS standard (MODIS-ST) product (Level2, MAC04S0.002, "AOD_550_Dark_Target_Deep_Blue_Combined" ) .

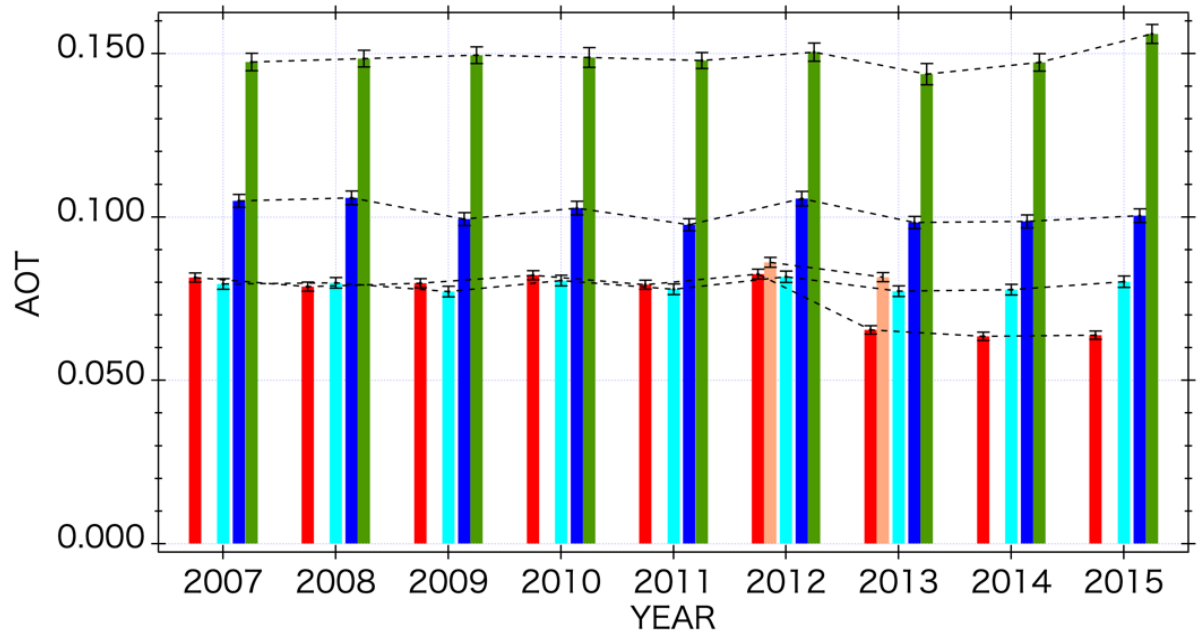

This Study (Ver.3)

This Study (Ver.4)

CALIOP-ST (Ver.3)

CALIOP-ST (Ver.4)

MODIS-ST

Figure 3. Changes in the annual global AOT average value of each product for 9 years (2007-2015, only day-time). Error bars represent standard error. 


\section{SUMMARY}

The algorithm is developed to (1) distinguish four components of the aerosol by using CALIOP data ( 2 wavelengths, 1 polarization) and (2) retrieve their extinction coefficient. These results show that WS and DS account a large fraction of total AOT.

Comparisons of our products with other products are conducted for 9 years. The geographical pattern of total AOT is similar between our results, CALIPSO-ST, and MODIS-ST. The global mean values of our results are smaller than CALIPSOST(Ver.4) and MODIS-ST, while the interannual variation of AOT is less than $10 \%$ from 2007 to 2011 for all four products.

We plan to perform the comparison of total AOT between our results and the AERONET groundbased measurement to understand the reason for the underestimation of total AOT in our results.

\section{ACKNOWLEDGMENTS}

CALIPSO data were obtained from the Atmospheric Sciences Data Center at NASA's Langley Research Center. This study was supported by JSPS KAKENHI Grant Numbers JP17H06139, JP15H02808, JP15H01728, JP2524707, and by the Japan Aerospace Exploration Agency for EarthCARE Research Announcement.

\section{REFERENCES}

[1] Nishizawa, T., H. Okamoto, N. Sugimoto, I. Matsui, A. Shimizu, and K. Aoki, 2007, An algorithm that retrieves aerosol properties from dual-wavelength polarization lidar measurements, J. Geophys. Res., 112, D06212, doi:10.1029/2006JD007435.

[2] Nishizawa, T., H. Okamoto, T. Takemura, N. Sugimoto, I. Matsui, and A. Shimizu. 2008, Aerosol retrieval from two-wavelength backscatter and one-wavelength polarization lidar measurement taken during the MR01K02 cruise of the R/V Mirai and evaluation of a global aerosol transport model, J. Geophys. Res.. 113, D21201, doi:10.1029/2007JD009640.
[3] Nishizawa, T., N. Sugimoto, I. Matsui, A. Shimizu, and H. Okamoto, 2011, Algorithm to retrieve aerosol optical properties from twowavelength backscatter and one-wavelength polarization lidar considering nonsphericity of dust, Journal of Quantitative Spectroscopy and Radiative Transfer Papers 112, 254-267.

[4] Kudo et al., 7th International EarthCARE science workshop (2018/6).

[5] Kudo, R., Nishizawa, T., and Aoyagi, T.: Vertical profiles of aerosol optical properties and the solar heating rate estimated by combining sky radiometer and lidar measurements, Atmos. Meas. Tech., 9, 3223-3243, https://doi.org/10.5194/amt9-3223-2016, 2016.

[6] Hess, M., P. Koepke, and I. Schult, 1998: Optical properties of aerosols and clouds: The software package OPAC. Bull. Amer. Meteor. Soc., 79, 831-844.

[7] Smirnov, A., Holben, B. N., Kaufman, Y. J., Dubovik, O., Eck, T. F., Slutsker, I., Pietras, C., and Halthore, R. N.: Optical properties of atmospheric aerosol in maritime environments, J. Atmos. Sci., 59, 501-523, 2002.

[8] Michael Kahnert, Timo Nousiainen, and Hannakaisa Lindqvist, "Models for integrated and differential scattering optical properties of encapsulated light absorbing carbon aggregates," Opt. Express 21, 7974-7993 (2013).

[9] Erickson, D. J., and Duce, R. A.: On the global flux of atmospheric sea salt, J. Geophys. Res. 93, 14079-14088 (1988).

[10] Aoki, T., Y. Tanaka, A. Uchiyama, M. Chiba, M. Mikami, and J. R. Key, 2005: Sensitivity experiments of direct radiative forcing by mineral dust using spectrally detailed radiative transfer model, J. Meteorol. Soc. Japan, 83A, 315-331.

[11] Kaufman, Y. J., L. A. Remer, D. Tanr'e, R.R. Li, R. Kleidman, S. Mattoo, R. Levy, T. Eck, B. N. Holben, C. Ichoku, J. Martins, and I. Koren (2005), A critical examination of the residual cloud contamination and diurnal sampling effects on MODIS estimates of aerosol over ocean, IEEE Trans. on Geoscience \& Remote Sensing, 43(12), 2886-2897. 